\title{
Dynamics Analysis and Simulation of Roll Grinder Components
}

Yuan Qingni ${ }^{1}$, Lu Jian ${ }^{1}$, Pan Weiji ${ }^{1}$, Yuan Qingyun ${ }^{2}$

${ }^{1}$ Key Laboratory of Advanced Manufacturing Technology (Guizhou University), Ministry of Education, Guiyang 550003, China; Email: cme.qnyuan@gzu.edu.cn

${ }^{2}$ Guiyang Dongsheng Patent and Trademark Affairs co., LTD, Guiyang 550002, China)

This essay aims to identify the composite motion and the cutting force between the grinding wheel and roller of the roll grinder. Based on the analysis of roll grinding mechanism, this essay further uses Newton's law which describes linear motion and Euler equation which describes rotation to build rolling components' Newton-Euler dynamics equation. Then the essay simplifies rolling components' virtual prototype, and uses the dynamic analysis function of ADAMS to do dynamics simulation analysis of rolling components. Finally, based on the formula to calculate grinding force, this essay testifies that calculated results are consistent with simulation results, thus providing reference data for optimization.

Keywords: Rroll grinder, Rimulation, Dynamics analysis, ADAMS

\section{Acknowledgement}

This paper is supported by Guizhou Province Science and Technology Office Project for " Key Laboratory of Construction of Digital Cultural Heritage Protection in Guizhou Province " (Guizhou Branch Total Z [2013] 4005), National Science and Technology Support Program Mission Statement for " Tourism industry demonstration for digitization of cultural heritage, cultural protection and development of minorities Features "(2014BAH05F00), Guizhou Province Science and Technology Fund Project for " Manufacturing -oriented research and application of service model "(Guizhou Branch Total J [2012] No. 2130), workstation planning of machine man-machine engineering in Guizhou.

\section{References}

[1] DUAN BINHUA. (2011). Design of super-heavy CNC roll grinding machine [J]. Precise Manufacturing \& Automation, (3):24-28.

[2] CHEN Ch. (2013). Development of Full Automatic Heavy NC Roll Grinder [J]. MACHINE TOOL \& HYDRAULICS, 2013.41(8):50-53.

[3] WANG-Le, NIE, X. (2014). Error Analysis and Improvement of Rol Grinder Online Measurement Devic[J].Machinery Manufacturing \& Automation,(1):73-75.

[4] ZANG, H., JIANG S. (2009). Dynamic Design of Structure for Big Roller Grinding Machine [J]. Design and Research, (4):66-69.

[5] GU, W., YAO Z., HU J. (2007). Dynamic analysis of micro-feed mechanism in high-speed roller grinding machine[J]. Journal of Engineering Design, 2007.14(6):460-463.

[6] http://baike.baidu.com/view/2548176.htm?fr=aladdin.

[7] LI, B., ZHAO, B. (2003). Modern Grinding Technology [M]. China Machine Press, 2003,6.

[8] MALKIN,S. (2002). Grinding technology theory and application[M]. Translated by Cai Guangxi, et al. Shenyang: northeastern university press, 2002.

[9] XIANGZHOU, Z., GUOYUAN, T. (2010). Mechanical system virtual prototyping technology [M]. Higher Education Press.

[10] GOVINDHASAMY, J. J., MELOONE, S. E., IRIN G. W. Neural modeling, control and optimization of an industrial grinding process [J]. Control Engineering Prairie, 2005, 13:1243-1258. 